\title{
Towards improved management of coastal submersion crises - CRISMA-WAVE solution as an example of CRISMA Framework application
}

\author{
Marc Erlich ${ }^{1, a}$, Christophe Coulet ${ }^{1}$ and Arnaud De Groof ${ }^{2}$ \\ ${ }^{1}$ Artelia Eau et Environnement, 6 rue de Lorraine , 38130 Echirolles, France \\ ${ }^{2}$ SPACEBEL, Liège Science Park, Rue des Chasseurs Ardennais 6, 4031 Liège, Belgium
}

\begin{abstract}
Coping with various types of natural or man-made hazards the FP7 SECURITY CRISMA project (http://www.crismaproject.eu) has designed and developed an experimental software framework allowing building crisis management simulation application. One of the five pilot applications of CRISMA dealing with preparedness to the coastal submersions was developed and implemented using return of experience of the reference Xynthia storm surge event in the Charente Maritime County in France. The paper addresses the generic CRISMA Framework applicability to simulate mitigation effects of a coastal submersion through CRISMA-Wave implementation of a full modelling cycle. The CRISMA-Wave paradigm reflects user needs for simulation of "what-if" scenarios for short and long-term actions and the paper describes in particular its different components : *Simulation of submersion effects at a range of temporal and spatial scales, *Preparedness Planning, *Assessment of impacts depending on scenarios based on options for managing the inundation risks, *Cascading effects and *Evaluation of damages with comparison of submersion defence scenarios based on cost-benefit and multi criteria analysis.
\end{abstract}

\section{Introduction}

Recently completed the EU FP7 SECURITY project CRISMA (www.crismaproject.eu) - "Modelling crisis management for improved action and preparedness" has developed a generic methodology and software framework for the implementation of simulation-based decision support systems [1]. CRISMA targeted use cases in the preparatory phase of crisis management: short and long-term planning, desktop training and assessment in field trainings. Application prototypes cover different types of hazards (floods, snowstorms, earthquakes, forest fires, accidental pollutions, mass accidents) and illustrate how the CRISMA Framework can be used in a relatively simple but integrated manner to develop fully fledged decision support applications. A generalized workflow of a CRISMA application is depicted in the Figure 1.

The applications allow the decision maker to visualise the state of the world during the evolution of a crisis and help to compare such a state with possible alternative states that may be the result of certain decisions and emerging events. The selection of alternatives to be simulated and the selection of criteria and ranking criteria that are used for world state comparison are normative decisions. Depending on the concrete application, these decisions can either be taken in the setup phase or within the interactive decision-simulation-assessment loop. CRISMA applications do not impose decisions, but allow comparing effects of various decisions (e.g. variant investments or tactical measures) [2]. The general preparedness of the stakeholders for risks and related crisis situations need to be improved by developing new approaches and solutions. As preparedness and response cannot be separated from each other, thus effective crisis management is calling for an adequately designed preparation phase.

\footnotetext{
${ }^{a}$ Corresponding author: marc.erlich@arteliagroup.com
} 


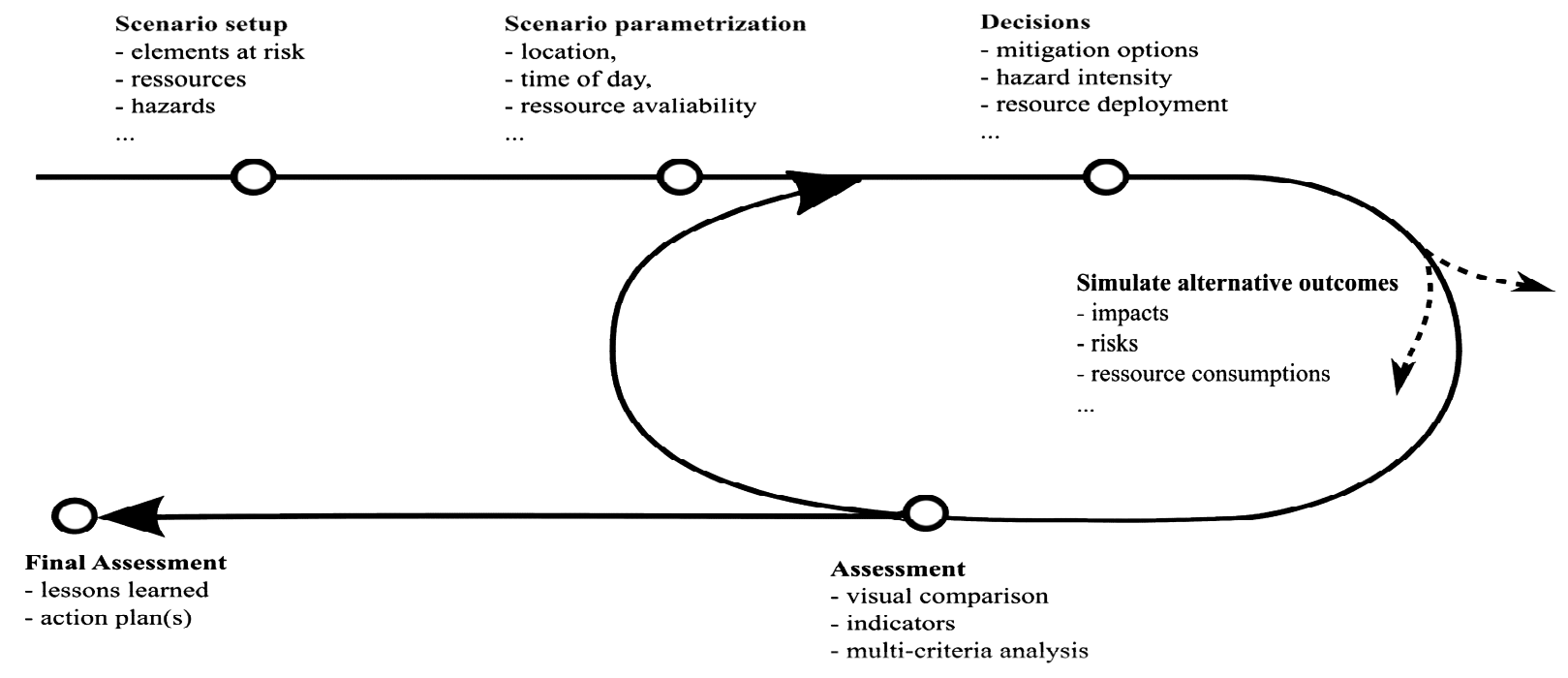

Figure 1 Generalised workflow of a CRISMA application (from [3]

In order to simplify application development and data analysis, CRISMA applications always produce a series of snapshots of the simulated world [1]. Such snapshot is called "World State", and it contains all information that is needed to analyse the situation or re-start the simulation from a particular World State point. A change from one World State to another is called World State transition (Figure 2). The world state transition maintains the structure of the world state and does neither change the dimension of the simulated world nor the type of elements that constitute the world state.

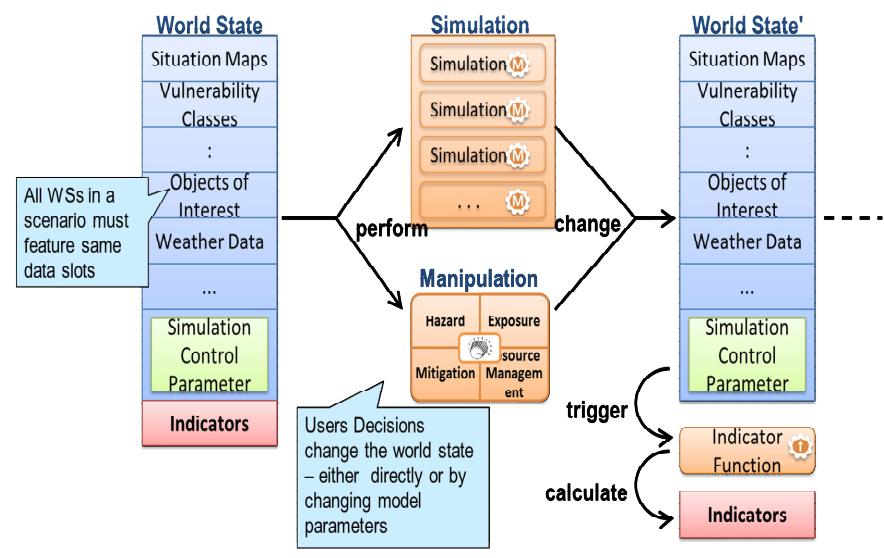

Figure 2 World States and World State transitions (from [2])

\section{CRISMA-WAVE as a solution for simulation of coastal submersion scenarios}

The CRISMA-WAVE prototype is based on the generic, hazard-neutral CRISMA Framework that is the result of the fundamental system developments achieved by the CRISMA Project [4]. This framework provides all necessary building blocks in order to construct a complex crisis management system. The building blocks are generic, configurable, composable, reusable and adaptable. They are the core elements of the architecture and encapsulate the functionality of the CRISMA Framework. These functionalities can be offered by existing software components or by components developed from scratch. Several software components can meet the building blocks requirements. In this context, the developer selects the best building block configuration adapted for a specific application of a crisis management system. For the purpose of an application development three types of building blocks are identified:

- Infrastructure building blocks - core of the CRISMA Framework,

- Integration building blocks - elements that support the data and model integration,

- User interaction building blocks - graphical users interfaces core elements.

The development of a new crisis management system is independent and flexible. It can be carried out using a limited number of building blocks. For example, during the project, the CRISMA Framework was used aiming to develop five applications linked to specific scenarios:

- Extreme winter crisis in the north of Europe

- Coastal submersion defense strategies for the Charente-Maritime county

- Earthquake and forest fire application

- Accidental spillage from a container at a large city port

- Mass-casualty incident

Each application is based on specific building blocks that are not necessarily used in the other applications. Indeed, they can be not suited in regard to the crisis management purpose of the application. In addition, the crisis management systems can also integrate specific simulation models thanks to the integration building blocks. The CRISMA-WAVE is the result of the coastal submersion defence strategies for the Charente-Maritime county application. 


\subsection{CRISMA-Wave functional architecture}

The Figure 3Figure 3 shows the interactions between each component of the architecture and identifies the type of each building block.



Figure 3 CRISMA-WAVE functional architecture (from [5])

The following building blocks compose the CRISMA-WAVE prototype architecture :

Integrated Crisis Management Middleware (ICCM - Infrastructure building block) - The ICMM is the core of the system. This building block is mandatory for all system because it is the control and communication information hub. It connects the building blocks used in a given application, collects and stores all information regarding to data, simulation models, manipulations, indicators, etc.

Data integration (Integration building block) - This components is used to serve data in a compliance way. For geo-spatial data, the Open Geospatial Consortium $(\mathrm{OGC})^{\mathrm{a}}$ standards are used such as Web Map Service ${ }^{\mathrm{b}}$ (WMS), Web Feature Service ${ }^{c}$ (WFS). It allows publishing geo-spatial results from the different models used in the CRISMA-WAVE. The open source server, GeoServer ${ }^{\mathrm{d}}$, has been selected for this building block.

Simulation Model Integration (Integration building block) - This components exposed the models and

\footnotetext{
${ }^{a}$ http://www.opengeospatial.org/

$\mathrm{b}$ http://www.opengeospatial.org/standards/wms

c http://www.opengeospatial.org/standards/wfs

$\mathrm{d}$ http://geoserver.org/
}

proposed to launch the processing in a compliance with the OGC standard, Web Processing Service ${ }^{\mathrm{e}}$ (WPS). The Open Source implementation of the WPS, PyWPS ${ }^{f}$ was selected for CRISMA-WAVE.

Simulation model interaction (User interaction building block) - It allows a user to discover and to run processing delivered towards the WPS.

World State management (User interaction building block) - This component provides different widget to discover and visualise the World State metadata.

GIS view (User interaction building block) - The GIS view allows users to visualise and manipulate the geospatial data. The GIS functionality is operated by the open source library, OpenLayers ${ }^{\mathrm{g}}$.

Mutli-criteria analysis and decision support (User interaction building block) - This components allow to compare and to perform ranking of different management scenario.

Moreover, the following models or algorithms have been implemented for the CRISMA-WAVE:

\footnotetext{
e http://www.opengeospatial.org/standards/wps

$\mathrm{f}$ http://pywps.org/

$\mathrm{g}$ http://openlayers.org/
} 
Coastal Submersion model - This 2D-hydrodynamic model is based on the open source TELMACMASCARET system ${ }^{\mathrm{h}}$. This system has been configured for the Charente-Maritime County appropriately to two spatial scales: regional and local, allowing the user simulation of the evolution of a coastal submersion event for a fixed time period (usually between 24-48 hours). During this period, the models deliver new results every five minutes for different hydrodynamic variables such as water levels, velocities, fluxes, discharges. In the principle any storm surge impact hydrodynamic simulation legacy system coping with spatial information can be integrated as a coastal submersion model.

Dikes Vulnerability model - Based on the dike's physical status, this model calculates the potential statistical impacts of the storm surge. This model is based on the damage probability matrix and has been realised in Python. It informs users on potential breach or failure of dikes.

Building impacts - This Python algorithm allows estimation of number of flooded buildings depending on the water level. This script used directly the result of the coastal submersion model at a local scale.

Damage analysis - Based on the building impacts, this Python algorithm calculates the potential cost of the building damages resulting from coastal submersion using two methodologies acknowledged by the French administration:

Method 1: based on Torterotot's method [6] and the costs estimation reflecting return on experience surveys after Xynthia storm surge;

Method 2: based on the new French national recommendations for estimation of damages due to inundations [7]. The latter provides lower estimates of building damages than the first as it takes into account depreciation factor of constructions.

Two other models have been also tested in the CRISMA-WAVE application however they aren't deployed with the system due to commercial and use restrictions. Under CRISMA-WAVE prototype application the results of these models were integrated in order to simulate evacuation on a specific area of interest, Les Boucholeurs, a borough of the Châtelaillon municipality in the Charente-Maritime County particularly affected during the Xynthia event.

DynaPop Model [8] - This model calculates the distribution of the population between spatio-temporal grids. The result of the distribution in the CharenteMaritime was used as input for the evacuation model.

\footnotetext{
${ }^{\mathrm{h}}$ http://www.opentelemac.org/
}

Evacuation model - The evacuation, agent-based model used the software Life Safety Model 2D ${ }^{\mathrm{i}}$ (LSM2D). This model allows performing different evacuation scenarios depending on a number of roads closed due to inundations, the estimated casualties on population, and the estimated impacts on buildings due to the flood. Developed by $\mathrm{BC}$ Hydro it was further interfaced with TELEMAC-2D and used by HR Wallingford [9].

In addition to these components, a security layer has been deployed in order to handle user authentication in the application. Internationalization has been also introduced to support multi-language versions and as per today English and French interfaces exist.

\subsection{User interface}

Aiming to provide the best experience to the users, different group of interactions have been defined. These groups are directly linked to one or several building blocks of the CRISMA Framework. The users discover the different functionalities of these building blocks towards four specific sections (accessing via the tabs):

Catalogue (Figure 4) - All metadata related to the scenarios and their different World State (WS) can be discovered by the users thanks to this function. The main characteristics of each WS are described such as the title, the description, the data, the indicators... In addition, the web application allows visualization of the data provided by the WS.

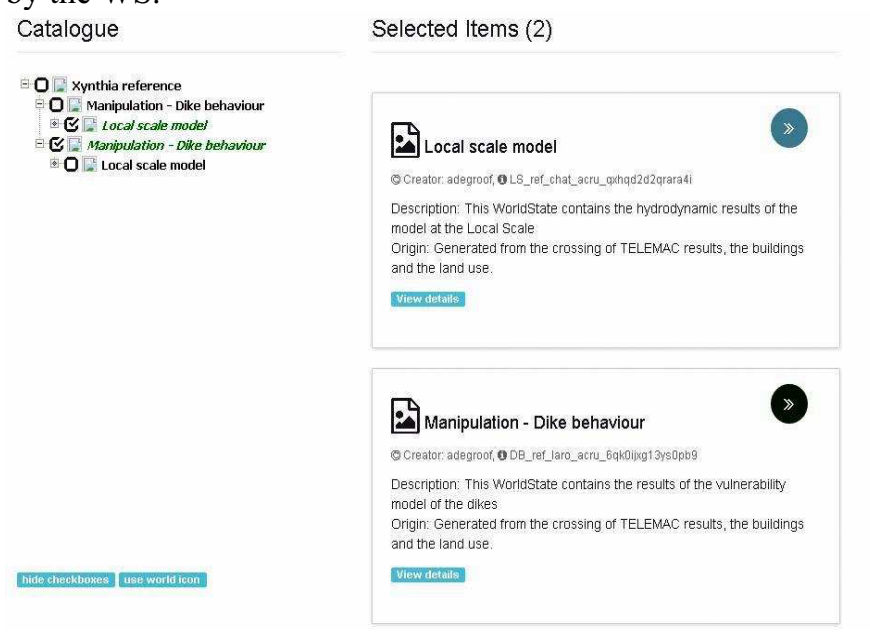

Figure 4 Catalogue interface

World State (Figure 5) - This section allows creating new scenario. Following a specific time line of actions (see detailed description in the section 3 of this paper), the user builds his scenario. During this sequence of actions, the users can modify the dike vulnerability and interact with models of the CRISMA-WAVE: coastal submersion model (regional and local), dikes vulnerability model, building impacts, and the cost impacts. For example, the user can select different options that will influence the dikes behavior and the results of the different simulations. The result of each

\footnotetext{
${ }^{\mathrm{i}}$ http://www.lifesafetymodel.net/
} 
models are displayed on a map viewer or in specific tables.



Figure 5 World State web client indicators

In addition to the geo-spatial results of the models, some indicators can be also calculated by models. For example, the dikes vulnerability model provides the number of dike sections where the damages such as breaches or failures occurred; the building impacts provide the number of flooded houses by class of attaint water level. The following Figure 6 displays an overview of these indicators for each scenario. By this way, the user can compare the results of the simulations based on his decision for a coastal submersion event.

\begin{tabular}{|c|c|c|c|c|}
\hline & \multicolumn{4}{|c|}{ Reference scenario } \\
\hline Vuherablity model & Decrease VUnerability & No fallure (dkes +50 ) & No failure & Xynthia Vunnerabilty \\
\hline 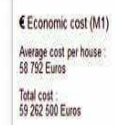 &  &  & 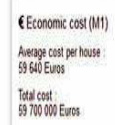 & 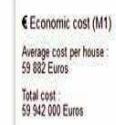 \\
\hline  & 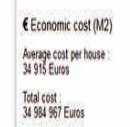 & 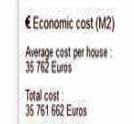 & 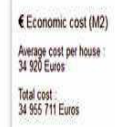 & 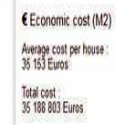 \\
\hline 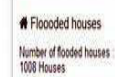 &  & 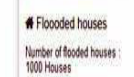 & 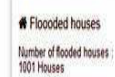 & 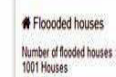 \\
\hline
\end{tabular}

Figure 6 Key Performance indicators for a coastal submersion damage scenario

Decision Support (Figure 7) - Based on the different indicators, this section performs a multi-criteria ranking of different scenarios. The user must define two parameters:

-The criteria functions that map indicator values to levels of satisfaction for the users. For example, the user is totally satisfied if the number of flooded houses is less than 10 . He is partially satisfied if this number is between 11 and 30, and he is unsatisfied is the number exceed 30 .

- The decision strategy that provides a weight to be assigned to each indicator. For example, the damage costs have a strategic importance in comparison of the number of breach or failure on the dikes. The weight given to the damage costs will be greater.

This CRISMA Framework function addresses the challenge of multi-criteria decision-making through the generation of a score that can be used for ranking scenarios. This concept is based on the ordered weighted averages (OWA) method ([10]). However, it is worth mentioning the French administration advocates use of equivalent system of weights, without preferences.

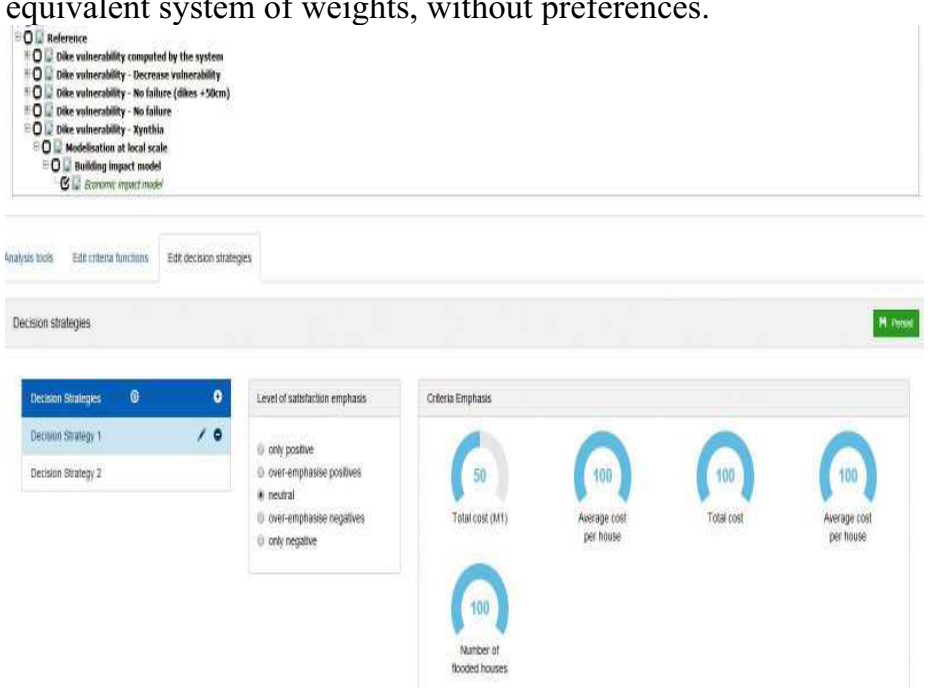

Figure 7: Decision Support GUI layer

After, several iterations and user feedbacks, the GUI has been adapted in order to propose a simple and more intuitive design to the users. A flat dashboard design has been adopted and several generic building blocks have been customized for the CRISMA-WAVE users such as the GIS view and the simulation model interaction.

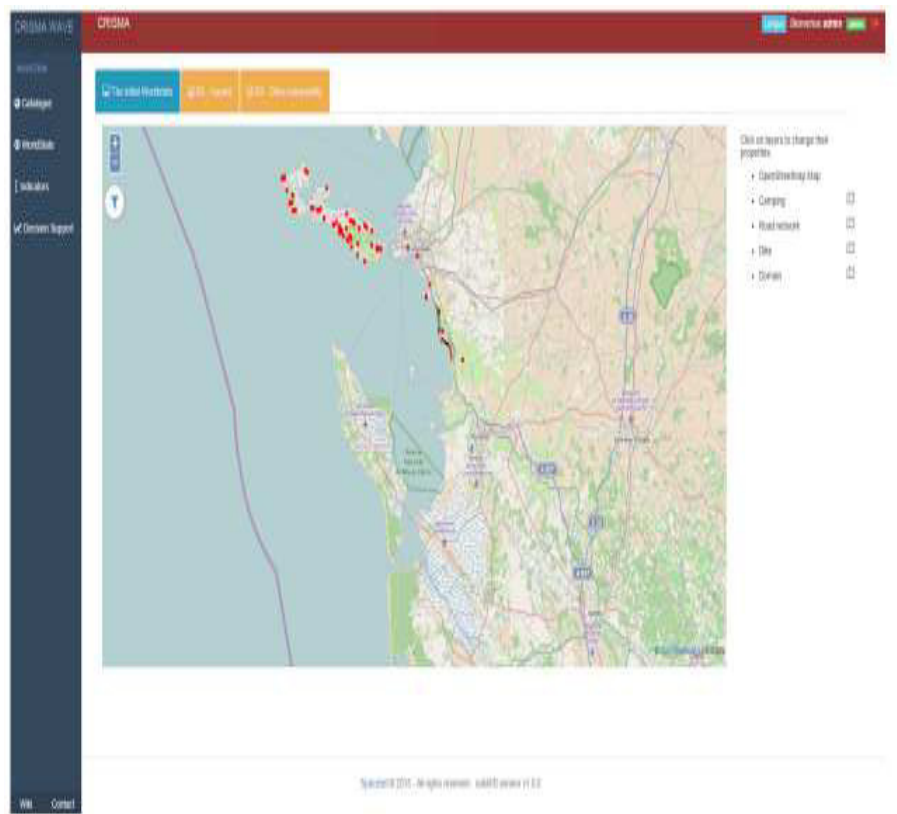

Figure 8 The dashboard of the CRISMA-WAVE 


\subsection{Implementation principles}

On the server side of the CRISMA-WAVE infrastructure, three servers have been deployed:

-Web-based platform - this server hosts the web application and the user interaction building blocks. Node.jsj is used for the deployment of the web application.

- ICCM instance - this server hosts the infrastructure building block

- Web services - This server hosts the following integration building blocks : data integration (GeoServer) and simulation model integration (PyWPS)

The frontend of the CRISMA-WAVE is based on HTML5, JavaScript (AngularJSk) and CSS3. The user interaction building blocks have been developed with the same components.

\section{Example of CRISMA-WAVE application in Charente-Maritime County}

Analysis of the response to the crisis situation generated by Xynthia storm surge event on 27-28 of February 2010 drew a public attention to a lack of preparedness of the authorities and the population to a catastrophic event of such dimension. One of the main recommendations of the French Audit Court [11] concerned an urgent need for specific tools for the assessment of a crisis preparatory phase with priorities on coastal flood risk awareness and strengthening the crisis management stakeholders' capacity of simulation of disaster consequences.

In view of these problems, the application of CRISMA-WAVE was designed to address the following two major issues:

- a better assessment of potential impacts (social, ecological, utilities, activities) during a coastal submersion,

- a better preparedness management.

The application is composed of two main parts. First, corresponding to a regional scale (RS) of the county (total surface $>6800 \mathrm{~km}^{2}$ ), allows to perform an overview end evaluation of the exposure to the submersion risk. The purpose of this process is to obtain a synoptic view of the pilot region in order to estimate the extent of the event, the way it will reach the coast and the potential global impacts (e.g. which dikes will be overflowed or weakened). Considering the potential impact magnitude of the event, local crisis management stakeholder resources may not be sufficient and the help from the neighboring counties and/or at a national scale would be required. Large scale considerations are also relevant in order to incorporate the effect of a potential

\footnotetext{
${ }^{\mathrm{j}}$ https://nodejs.org/en/

${ }^{\mathrm{k}} \underline{\mathrm{https} \text { ://angularjs.org/ }}$
}

combined effect of river flood in the Charente river basin in the hydrodynamic submersion model.

Second, corresponding to a local scale (LS) $(\sim 200$ $\mathrm{km}^{2}$ ) evaluation of exposure to submersion should allow estimating the potential impacts more precisely both in time and space. Indeed, in the scope of the coastal submersion preparedness phase, it is important to evaluate the potential damages of dikes, the potential impacts (social, ecological, utilities, activities) and the risk of cascading effects, which may follow. With these results it should be possible for the decision makers to propose appropriate mitigating actions and reprocess the system in order to re-evaluate the impacts of the proposed mitigation measures.

Moreover, the different phases of crisis management are realized by several actors at regional or local scale. They can, then, be conveyed into main roles. The first actor is the population who is the main affected group. In France, the organization of the different crisis stakeholders is the same in all regions therefore a coastal submersion preparedness model suitable for the Charente-Maritime County can be considered as a generic model for French organisation of crisis management.

At a county scale, the Interdepartmental Service of Defense and Civil Protection (SIDPC) is in charge of the overall crisis management in the county (response authority). It is focused on the security of the population.

The county self-government (Conseil Général) is in charge of two flood protection and control domains:

-maintenance and the monitoring of water works (dikes survey in the case of Charente-Maritime),

-management of every type of impacts (social, economic and ecological) as far as land use and land planning is concerned, for mitigation purposes (responsibility of a planning authority).

The county Service of Fire and Emergency (SDIS) organises the operational response in the field (operational response authority). These crisis management stakeholders give indications to mayors of communities who organize the response and recovery phases in their municipalities.

\subsection{Data}

\subsubsection{Assets data sets}

The required information of assets for the application is used to assess the vulnerability and the impacts of coastal submersions in the studied area. Then, the assets to be included in the world state should represent the different objects such as :

- $\quad$ road and train network,

- buildings,

- dikes,

- camping sites

\subsubsection{Expert data sets}

The expert data sets are special data required by simulation models. They have to be prepared and 
provided by an expert. In the case of coastal submersion, these data are mainly necessary to run the workflow of TELEMAC-2D for hydrodynamic simulations and optionally the evacuation model due to their specificity and complexity (e.g. specific input data for the setup up the DynaPop population distribution model).

\section{Hydrodynamics model data :}

-dikes height and quality status as assessed by field measurements (used also in dikes vulnerability model),

-evolution in time of the mean sea level at the marine boundary comes from tidal measurements,

-the wind velocity (time, direction, intensity),

-description of flood defences from field measurement,

-swell data from a swell model TOMAWAC, which is a module of Open-TELEMAC- Mascaret System),

- functional data files containing geometry, boundary conditions and parameters,

\section{Vulnerability model data:}

- link between section dikes and node dikes,

-dikes status shapefile,

- dikes height and quality comes field measurement

\section{DynaPop Model data:}

-population data (census, workforce, commuting, tourists, etc.),

-time use data (from INSEE 2009-10 French time use survey),

-land use data

\section{LSM Model data:}

-population distribution from the DynaPop model,

-road network (data by IGN, BD TOPO national data bases),

-buildings (data from IGN, BD TOPO national data bases)

- localisation of shelters and warning centers,

-result of hydrodynamic model

\subsection{Illustrated example of a system exploitation}

In order to use this application, all the required models should exist on the area of interest and the various data used should be also available. We didn't detail the building of model and the implementation of the data. We just precise here that all the data used are stored in some database and the evolution of the local situation should be easily take in account by upgrading the concern databases.
The way the use of CRISMA-WAVE is envisaged takes the form of a double loop as presented in the following workflow (Figure 9).

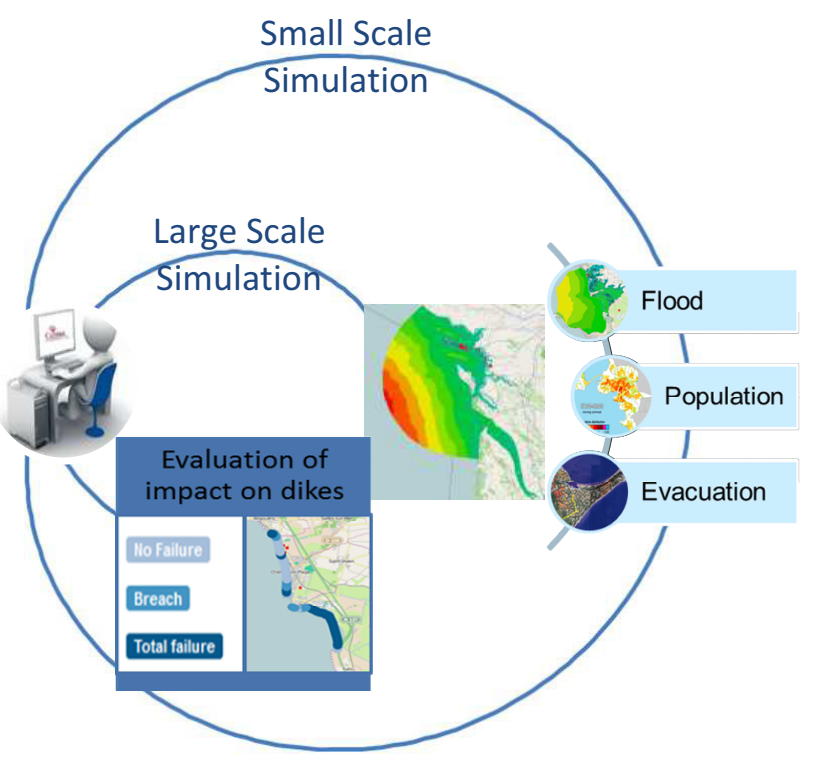

Figure 9 CRISMA-WAVE large scale (LS) and small scale (SS) concepts

The result of this large scale simulation provides two types of information:

- a global overview of the potential inundated area due to the overflowing or overtopping of dikes;

- an evaluation of the impact of this event on dikes which classify each segment of dike (dikes are considered in this model as a successions of elements of about $250 \mathrm{~m}$ length) in 3 categories according to the highest probability of no failure, breach appearance or dike's total failure

According to these first synoptic results, the user can decide:

- to stop the process (if there are no identified risks);

- to restart the process with another meteorological event boundary conditions;

- to go further and make a focus on one or more local areas of interest, usually corresponding to the hot-spots identified at a large scale.

A local scale simulation requires user defined rule for dikes behavior according to the 3 categories listed previously.

As a first, rough estimation for the local simulation the user could accept the proposed evaluation taken form the large scale simulation. In this case, all elements marked with:

- $\quad$ total failure will be considered as collapsed;

- $\quad$ breach will be considered with a breach of $50 \mathrm{~m}$ in the middle of the element;

- no failure will remain as there was in the initial state;

To test various scenarios in order to increase the preparedness level or to decide some mitigation measures, the user could also manually change the 
comportment element by element. Then it could run the small scale model and obtain a local view of the flooded area.

One of important questions related to crisis management concerns evacuation capacity of the population exposed to the inundation risk. Population distribution patterns do not only vary strongly in a spatially granular sense at the local level, but also significantly over time. In particular, in the context of an attractive coastal spa area of Charente-Maritime County, with a significant seasonal population the aspects of population dynamics required a specific attention. Developed as the CRISMA Framework building block, the DynaPop model [7] for population estimation in the area of interest disaggregates information on a regular $100 \mathrm{~m}$ spatial resolution grid with the time step of 1 hour.

Figure 10 illustrates a typical DynaPop output for the pilot study area around La Rochelle and Île de Ré. It compares the night-time situation to different daytime periods. It is obvious that certain areas that are sparsely populated during the night attract large numbers during the working hours (e.g. the port area). Also lunch time peaks are significant when workers distribute to restaurants in the surroundings as are morning and evening hours when the roads are much more frequented due to commuting traffic.

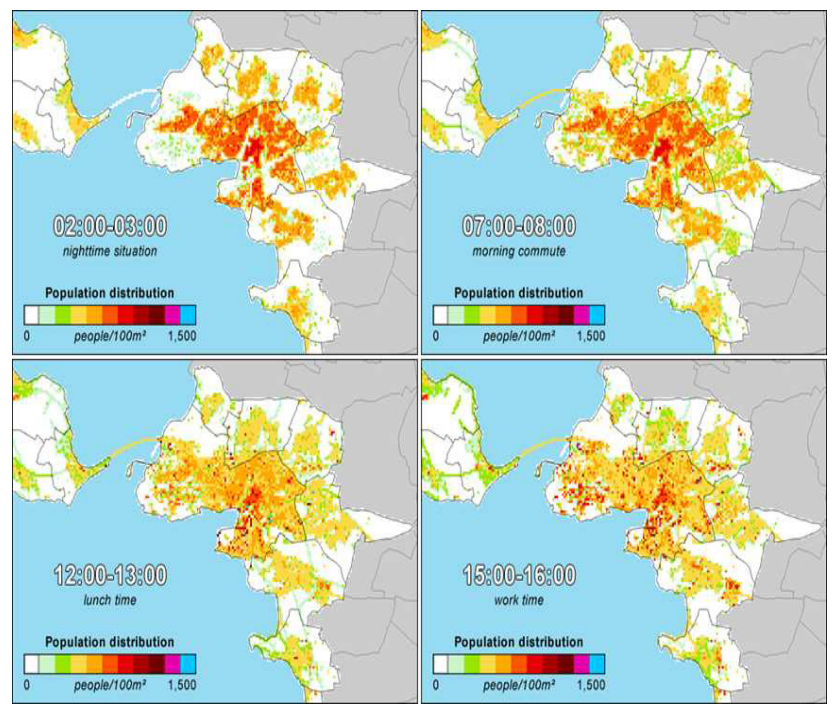

Figure 10 DynaPop dynamic population distribution model output for the La Rochelle and Île de Ré study area

The population dynamics provides boundary conditions to the evacuation model, which taking also into account the population behaviour (as a percentage of a total population respecting evacuation rules imposed by the authorities) allows identification of bottlenecks and isolated areas in case of a meteorological event Figure 11.

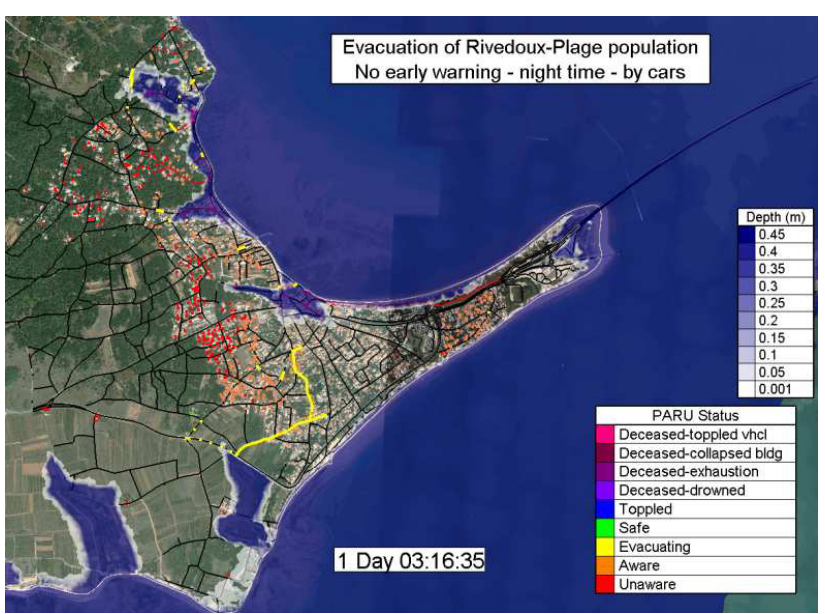

Figure 11 Example of LSM model of population evacuation by buses during flooding conditions of Rivedoux-Plage (Charente Maritime) without early warning, during night (i.e., the first person starts to evacuate when water level reaches his/her house. Then, the information to start evacuating spreads among the population).

In addition to the visual results of simulation, the tool produces under request some automatically computed indicators such as:

- number of flooded houses by class of water height;

- $\quad$ an estimation of damage costs;

- an evaluation of the number of fatalities and population remaining in the inundated areas

\section{Indicators}

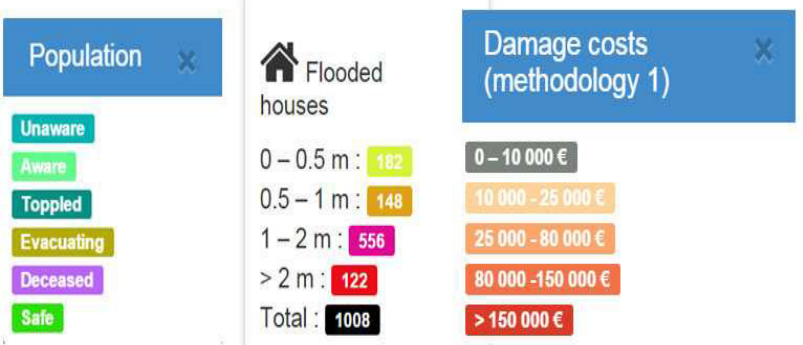

Figure 12 CRISMA widget for the definition of the indicators for scenario evaluation

Finally, in order to compare different scenario from the point of view of their use for the inundation crisis preparedness or for a purpose of evaluation of structural and no structural mitigation measures, the user can rank these scenarios (including older scenario results stored in the World State database) through a Multi-Criteria Analysis. 


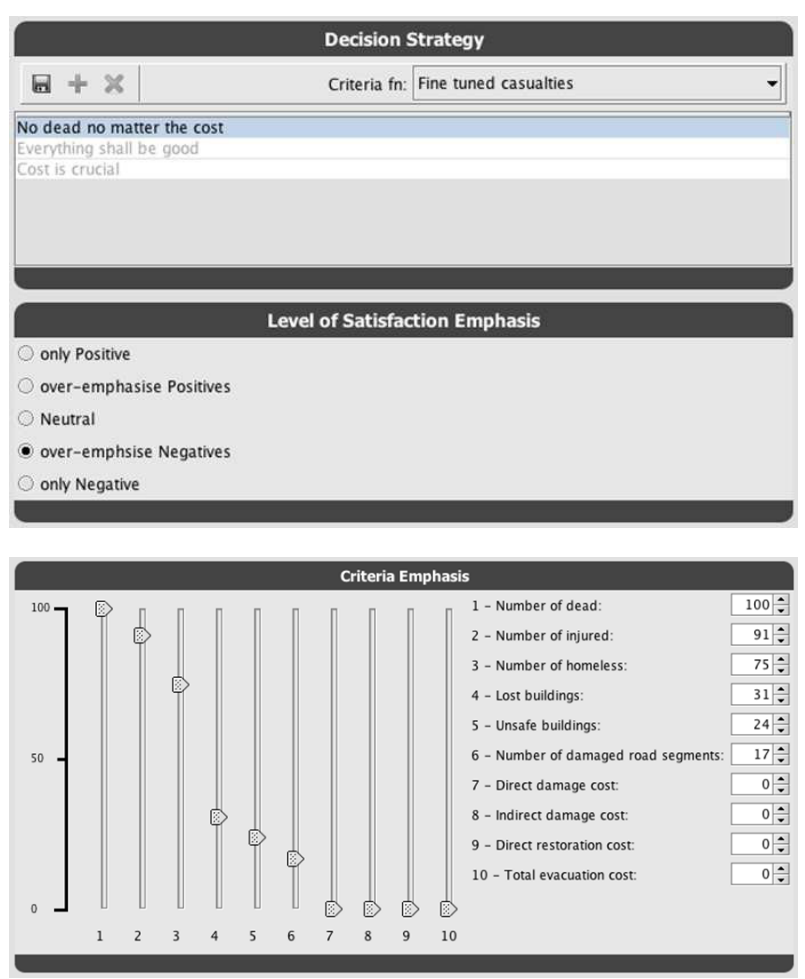

Figure 13 CRISMA widget for the definition of the decision strategy (from [5])

\subsection{Evaluation and validation}

The development of CRISMA Framework and all hazard specific thematic applications was performed in two iterations and submitted to a process of evaluation and validation by six appraisal groups composed both of partner development teams and end-users :

- Appraisal Group 1: crisis managers, deciders at high and middle level (for example civil protection agencies, self-government administration ...)

- Appraisal Group 2: deciders on tactical level (e.g. Red Cross organisations, fire brigades, health/emergency government administration...)

- Appraisal Group 3: dispatchers and trainers

- Appraisal Group 4: information officers (link with population, media...)

- Appraisal Group 5 : crisis domain specialists, exercise leader and exercise data stewards

- Appraisal Group 6 : CRISMA implementation teams (modelers, IT developers, integrators)

Both passive demonstrations and active on-line and hands-on experimentations were organized and allowed collection of direct feedback from end users. Evaluation and validation activities allowed assessment of the potential benefits of CRISMA Framework and its demonstrators but also identification of the remaining gaps and weaknesses and thus facilitating its adoption and further exploitation.

The CRISMA Framework evaluation methodology addressed two mains areas :
- Technical performance (efficiency) of applications (information systems) built using the CRISMA Framework. Tools developed and implemented were assessed to assure that they are compliant to the requirements set out in the specification documents and that the building blocks (components) of the ICMS interoperate as planned. Operability, reliability, robustness and flexibility of the CRISMA Framework were evaluated,

- Effectiveness of the tools developed in the project on a basis of the CRISMA Framework was evaluated through the assessment of the testing results of the implementations by user appraisal groups. The evaluation assessed the information quality and the end-user satisfaction and acceptance of the individual impact.

The evaluation process consisted in the answering of structured questionnaires by the members of Appraisal Groups and assigning of scores ranging between 1 (low mark) and 5 (very high mark). Samples of more than 120 questionnaires were collected and analysed during the evaluation process of the pilot applications.

The results of CRISMA Framework evaluation are positive and convincing for almost all selected criteria. While some of them are considered still at an early stage of Technological Readiness Level ${ }^{1}$ (TRL $=3-4$ ), others achieved a comprehensive level of maturity (TLR=5-7).

\subsection{Exploitation perspectives}

Currently, with respect to the agenda of the existing Flood Directive and its implementation in the EU member states, the European public administration, especially on the municipal and regional levels, should produce the reference documents needed for the protection of exposed populations against the inundation risks (Flood Risk Management Plans, Mitigation Measures Plan, etc.). The developed CRISMA-Wave prototype, once configured and instantiated for a particular geographical location, allows users to test, verify and compare different scenario results in a relatively simple way (what-if possibilities). It could also support crisis management stakeholders (civil protection, fire brigades) in order to enhance the preparedness with some "real" exercise.

The developed prototype CRISMA-WAVE corresponds to these needs, however it must undergo an industrialization process required for an operational use by the authorities.

As the conclusion of the CRISMA Framework evaluation process, the architectural and functional assumptions related to the developed Building Blocks were successfully validated through the experimentations with five various demonstrators. One of the objectives of the CRISMA Framework was to hide all complexity of implementation to the end user, so that he can focus on the relevant content rather than on programming effort. In

l'http://www.innovationseeds.eu/Virtual_Library/Knowled ge/TLR_Scale.kl 
this sense the usability of CRISMA Framework has been demonstrated by the implemented convincing pilot applications and reference applications. Although a progress has been made in this respect nevertheless a considerable integration effort was necessary in a case of some pilots impacting also the achieved TRL.

It is clear that the exploitation potential of the CRISMA results depends in large extent on the development of additional functions in such a way that the final services deployed can be completely adapted to the future end-user profile and requirements without a burden of low level programming effort.

\section{Conclusions}

The CRISMA Framework allows addressing management strategies of preparedness to both coastal and fluvial submersion issues through a comprehensive set of features including:

- the concept of a collaborative, modular, adaptable IT solution for the modelling of hazards and the simulation of crisis scenarios, for the purpose of training and preparation to decision making;

- a reference architecture to support the design and implementation of a simulation and decision support system;

- a toolbox consisting of generic and thematic building blocks/functions that are selected and integrated in a specific architecture tailored to the problem;

- $\quad$ simulation models addressing the representation of the physical phenomena, decisions and actions and impact (environmental, social, economic, etc.)

Using the CRISMA Framework the pilot implementation of CRISMA-WAVE in CharenteMaritime County in France offers the possibility of assessment and comparison of the impact of preventive measures (structural and non-structural) for coastal submersion, including preparation of mandatory (European Flood Directive, 2006) flood risk management plans for coastal and inland waters. The approach builds on an integrated assessment of flood hazards, vulnerability of flood risk exposed areas and allows analysis of territorial resilience to inundation risk of identified areas.

In particular the CRISMA-WAVE coastal Reference Application allows to:

- Define the physical parameters associated with a simulation scenario: tide height, run-up, wind speed and direction;

- Run coastal submersion simulations at global and local spatial scales for different Coastal Submersion scenarios;

- Calculate the simulation results (water level, water velocity, maximum water level, duration of submersion ...);
- Calculate the probability (likelihood) of damage to the protective works (e.g. dikes) and its extent;

- Simulate the modification of the protective works (dikes) behaviour (by introducing breach or total failure) aiming to run new simulations and evaluate the damages;

- Run an evacuation model as an assessment of the possible bottlenecks and isolated locations for a given hydraulic event;

- Compare the evolution of protective works and damages depending on hazard scenarios;

The simulation results are analysed using Key Performance Indicators related to:

- human health (number of people in flooded area, number of injured and dead people, number of evacuated population and homeless, number of isolated people remaining in the flooded areas), critical infrastructure (e.g. number and location of critical infrastructures in the flooded area, duration of their unavailability);

- environment (e.g. mean daily volume treated by the flooded treatment plants, capacity of stock and treatment of waste of the flooded plants, number of flooded IPPC or Seveso installations, quality of flooded areas (ecological status before flood) based on spatialised classification (CLC), quantity/quality of propagated materials (trees, waste, broken works, ...) based on flood intensity, economic damages (e.g. unitary costs for recovery of banks, wetlands, grass land, forest, ...);

- cultural heritage (e.g. Number of flooded patrimonial buildings and protected sites, Mean early number of visitors into the flooded museums);

- economy (e.g. costs to residential (material damages, Costs to firms, Costs to agriculture, Surface of flooded firms and housing, Daily traffic onto the flooded transportation facilities, Percentage of firms related to publics works which would be flooded, Number of working people into the flooded area, Surface of flooded agricultural areas, Duration of inactivity)

The simulated effects of coastal submersion at different temporal and spatial scales (varying from 1 minute to several days, from $1 / 100.000$ to $1 / 2.500$ ) allow assessing the impact according to selected scenarios based on options chosen to manage the risks through structural and non-structural measures.

The analysis of the economic aspect of potential damage reduction is performed using Multi-Criteria Analysis (MCA) and allows evaluation of the direct economic losses using damage functions per category of soil occupation, given the information of the maximum water level and duration of submersion per area and consequently to compare risk mitigation scenarios and rank them according to user defined sets of criteria and weights through Multi-criteria Analysis what ultimately 
can be used to build the coastal submersion crisis preparedness plans.

The CRISMA-Wave prototype has achieved a Technological Readiness Level (TRL) situated between 3 and 4. Further initiatives are being sought in order to industrialise CRISMA Framework, what would greatly improve the TRL and will position CRISMA-Wave as an environment suitable for operational use by crisis management stakeholders.

\section{References}

1. Dihé, P., Denzer, R., Polese, M., Heikkilä, AM. Havlik, D., Sautter, J., Hell, Th., Schlobinski, S., Zuccaro, G. (2013), An architecture for integrated crisis management simulation, $20^{\text {th }}$ Intl. Congress on Modelling and Simulation (MODSIM 2013), Adelaide, Australia, pp.873-879.

2. Dihé, P., Scholl, M., Schlobinski, S., Hell, T., Frysinger, S., Kutschera, P., Warum, M., Havlik, D., DeGroof, A., Vandeloise, Y., Deri, O., Rannat, K., Yliaho, J., Kosonen, A., Sommer, M., Engelbach, W. (2014). CRISMA ICMS Architecture Document V2, Deliverable D32.2 of the CRISMA Project, (http://www.crismaproject.eu/deliverables/CRISMA D322 public.pdf).

3. Havlik, D.,Engelbach, W.,Erlich, M., Meriste, M. (2015) Interactive virtual world models for crisis preparedness - better than the real thing?, in: S.Knezic (Ed.); The International Emergency Management Society -TIEMS-: Evolving Threats and Vulnerability Landscape: New Challenges for the Emergency Management : Proceedings of the International Emergency Management Society (TIEMS); 22nd TIEMS Annual Conference; Rome, Italy, Sept. 30 - Oct. 2, 2015, TIEMS, $11 \mathrm{pp}$.

4. Havlik, D., Dihé, P., Schlobinski, S. and Heikkilä, A.M (2015), Modelling crisis management for improved action and preparedness, VTT Technology T228, July, 62 pp.

5. Erlich M., Cabal A., Coulet, C., Daou M-P., Grisel M., de Groof A., Havlik D., Aubrecht C., Steinnocher K., Schlobinski S. and Zuccaro G. (2015). CRISMA Framework as an experimental tool for simulation of coastal submersion impacts and preparedness for crisis management, E-proceedings of the $36^{\text {th }}$ IAHR World Congress, 28 June -3 July, 2015, The Hague, The Netherlands, pp.1-11.

6. Torterotot, J.P. (1993) - Le coût des dommages dus aux inondations : estimation et analyse des incertitudes. PhD Thesis, Ecole Nationale des Ponts et Chaussées, (https://tel.archives-ouvertes.fr/tel00421862/document).

7. Analyse multicritères des projets de prévention des inondations. Guide méthodologique, Ministère de l'Ecologie, du Développement Durable et de l'Enérgie (2014). July 2014, http://www.developpement-durable.gouv.fr/IMG/ pdf/Ref___Guide_AMC_inondations.pdf.
8. Aubrecht C., Steinnocher K., Köstl M., Grisel M., 2015, Dynamic population exposure modeling: Application of DynaPop-X for storm surge related coastal flood crisis management. International Geoscience and Remote Sensing Symposium 2015 (IGARSS 2015). Milano, Italy, July 2015.

9. Lumbroso D.M., Sakamoto D, Johnstone W.M,Tagg A.F. and B.J. Lence (2011), The development of a Life Safety Model to estimate the risk posed to people by dam failures and floods, Dams and Reservoirs 21(1),31-43.

10. Yager, R.R. (1988), On ordered weighted averaging aggregation operators in multi-criteria decision making. IEEE Transactions on Systems, Man and Cybernetics, 18 (1), 183-190.

11. Cour des Comptes, (2012), Lessons from the 2010 floods on the Atlantic Coast (Xynthia) and the Var, Summary of the Public Thematic Report, July 2012. 